\title{
Effect of a Single Preoperative Dose of Oral Antibiotic to Reduce the Incidence of Surgical Site Infection Following Below-Knee Dermatological Flap and Graft Repair
}

\author{
Helena Rosengren ${ }^{1}$, Clare F. Heal' ${ }^{2}$, Petra G. Buettner ${ }^{3}$
}

\begin{abstract}
1 School of Medicine, James Cook University, Townsville, Queensland, Australia; Skin Cancer College of Australasia, Brisbane, Queensland, Australia; Skin Repair Skin Cancer Clinic, Townsville, Queensland, Australia 2 School of Medicine, James Cook University, Mackay, Queensland, Australia 3 Centre for Chronic Disease Prevention, James Cook University, Cairns, Queensland, Australia
\end{abstract}

Key words: antibiotic prophylaxis, surgical site infection, dermatological surgical wound infection, operative surgical procedures, grafts Citation: Rosengren H, Heal CF, Buettner PG. Effect of a single preoperative dose of oral antibiotic to reduce the incidence of surgical site infection following below-knee dermatological flap and graft repair Dermatol Pract Concept. 2019;9(1):28-35. DOI: https://doi.org/10.5826/ dpc.0901a08

Published: January 31, 2019

Copyright: $\odot 2019$ Rosengren et al. This is an open-access article distributed under the terms of the Creative Commons Attribution License, which permits unrestricted use, distribution, and reproduction in any medium, provided the original author and source are credited.

Funding: None.

Competing interests: The authors have no conflicts of interest to disclose.

Authorship: All authors have contributed significantly to this publication.

Corresponding author: Dr. Clare Heal, James Cook University, Mackay, Queensland, Australia. Email: clare.heal@jcu.edu.au

ABSTRACT Background: Surgical site infection (SSI) rates for below-knee dermatological surgery are unacceptably high, particularly following complex flap and graft closures. The role of antibiotic prophylaxis for these surgical cases is uncertain.

Objective: To determine whether SSI following complex dermatological closures on the leg could be reduced by antibiotic prophylaxis administered as a single oral preoperative dose.

Methods: A total of 115 participants were randomized to $2 \mathrm{~g}$ of oral cephalexin or placebo 40-60 minutes prior to surgical incision in a prospective, randomized, double-blind, placebo-controlled trial at a primary care skin cancer clinic in North Queensland, Australia.

Results: Overall 17/55 (30.9\%) controls and 14/55 (25.5\%) intervention participants developed infection $(\mathrm{P}=0.525)$. There was no difference between the study groups in adverse symptoms that could be attributed to high-dose antibiotic administration $(\mathrm{P}=1)$.

Conclusion: A single oral 2-g dose of cephalexin given before complex below-knee dermatological closure did not reduce SSI.

\section{Introduction}

The rate of surgical site infection (SSI) for clean dermatological surgery is usually less than $3 \%$ [1-3], which is significantly lower than the $5 \%$ acceptable SSI rate quoted by many authorities [4,5]. The incidence of SSI is influenced by body site, and certain anatomical sites are at much higher risk than the acceptable rate [6-9], with lower limb surgery most consistently complicated by infection [3,10-16]. In tropical North Queensland, the infection rates following excisions from the 
lower limb have ranged from $14.75 \%$ to $18.18 \%$ [13,16]. Below-knee surgery has been shown to have an even higher infection rate $[13,16,17]$. The reasons for this are unclear, but reduced perfusion pressure in the distal limbs [18], higher tension closures [19], as well as the frequent necessity for complex graft/ flap surgery are postulated reasons.

More complex skin closures, such as flap and graft procedures, are known also to be independently associated with significantly higher risk of SSI [20]. Large observational prospective studies have shown that flap repair increases the likelihood of infection by 2 to 15 times compared with simple elliptical closure [3,18,20,21]. Graft repair has also been linked to much higher infection rates [3,18,20,21].

Established SSI may require multiple medical visits, can result in poorer cosmetic outcome and significant bacteremic complications [8,17], and also requires several days of treatment with antibiotics. Antibiotic treatment may be associated with unpleasant side effects, allergy, and the development of antibiotic resistance [8]. As a result of indiscriminate antibiotic prescribing, antibiotic resistance is increasing at a dramatic rate, causing significant morbidity and mortality globally [22,23]. A single, high-dose preoperative oral prophylactic antibiotic has been proposed for anatomical sites and dermatological procedures at high risk of SSI [8]. It is suggested that administration of such a single prophylactic dose may be less likely to result in antibiotic resistance than a longer-term course prescribed for established infection, with a resulting reduction in the quantity of antibiotics prescribed overall $[17,19,24]$.

If antibiotic prophylaxis is to be effective, antibiotics should optimally be in the bloodstream and at the operative site at the time of incision [25,26]. The administration of antibiotics within 2 hours prior to incision is associated with the lowest risk of SSI [26].

\begin{tabular}{|c|c|}
\hline Inclusion Criteria & Exclusion Criteria \\
\hline $\begin{array}{l}\text { - Flap or graft dermatologic surgery } \\
\text { below knee } \\
\text { - Over } 18 \text { years of age }\end{array}$ & $\begin{array}{l}\text { - Ingestion of any antibiotic (other than } \\
\text { the intervention) within } 48 \text { hours of } \\
\text { surgery } \\
\text { - Suspected SSI at time of surgical closure } \\
\text { - Allergy to protocol suture or dressing } \\
\text { materials } \\
\text { - Allergy to cephalosporins or penicillin } \\
\text { - Intellectual or mental impairment } \\
\text { - Previous participation in this study } \\
\text { - Later exclusion if histology confirmed } \\
\text { the need for wider excision }\end{array}$ \\
\hline
\end{tabular}

Figure 1. Inclusion and exclusion criteria for study. [Copyright: @2019 Rosengren et al.]

Despite the importance of this topic, few randomized controlled trials (RCTs) have been published on the use of oral antibiotic prophylaxis in dermatological surgery [17]. The aim of our randomized, double-blind, placebo-controlled trial was to ascertain the effect of a single preoperative oral prophylactic antibiotic dose on SSI following complex below-knee dermatological surgery.

\section{Methods}

This randomized, double-blind, placebo-controlled trial recruited consecutive eligible patients booked for flap or graft closure following skin cancer excision below the knee at a primary care skin cancer clinic in Townsville, North Queensland, Australia, between January 2014 and February 2016. Each individual patient gave signed informed consent and was allowed to participate in the trial only once.

Specific exclusion criteria (Figure 1) were age under 18 , taking any antibiotic within 48 hours of the surgery, suspected SSI at the time of surgery, allergy to the protocol suture, dressing materials, cephalosporins or penicillin, intellectual or mental impairment, and previous participation in this study. If histology confirmed the need for a wider excision or participants received antibiotics for another SSI during the 30-day study period, participants were to be withdrawn from the study.
Capsules containing either $2 \mathrm{~g}$ of cephalexin or placebo were given 30 minutes prior to the excision appointment time, ensuring that skin incision would be within 60 minutes of ingestion of capsules. At the time of surgery baseline demographic data, pertinent medical and drug history, defect size, time from intervention to incision, and closure technique were documented. Histology was documented once it had been reported.

\section{Intra- and Postoperative Protocol}

If the wound required deep dermal absorbable sutures, Monosyn (B. Braun, Sydney, Australia) was used. All defects were closed superficially with nylon sutures (Dynek Pty Ltd., Hendon, South Australia). Following wound closure, Melolin (Smith and Nephew Medical Ltd, Hull, UK) and Fixomull (BSN Medical, Luxenburg) was applied.

Standardized verbal and written postoperative wound care instructions were given to all participants, stressing the importance of applying no topical creams, ointments, or antiseptics to the wound for the month after surgery. All participants were reviewed 7 days postoperatively for wound inspection and redressing. Information related to the use of postoperative oral analgesia (strongest analgesic used) was also recorded at this time. Early review at the study practice was encouraged in the event of discomfort, erythema, swelling, or discharge associated with the wound. 
1. At least ONE of the following:

- Purulent wound discharge

- Erythema $>1 \mathrm{~cm}$ from wound edges

- Localized swelling, pain or heat

2. Occurring within 30 days of surgery

Figure 2. Criteria for surgical site infection in dermatological surgery. [Copyright: C2019 Rosengren et al.]

Sutures were removed 14 days after surgery. If at the time of suture removal the wound had not fully healed, it was dressed again and regularly reviewed until it had completely epithelialized.

\section{Clinical Outcome}

The wound was assessed at the time of suture removal (14 days postoperatively) by 1 of the 6 treating doctors. An adapted version of the 1988 Centers of Disease Control and Prevention of National Nosocomial Infections Surveillance System definition for dermatological surgical site infection was used [27]. Standardized criteria for surgical site skin infection included occurrence within 30 days of surgery and purulent discharge, erythema more than 1 $\mathrm{cm}$ from wound edges, OR presence of localized swelling, heat, pain, or tenderness (Figure 2).

If SSI was suspected, a swab was taken for microscopy, culture, and sensitivity and a 5-day course of cephalexin (500 mg 4 times a day) was prescribed pending swab results. Each participant was phoned by the study nurse 1 month after surgery to ensure no SSI was inadvertently missed.

\section{Randomization and Blinding}

The randomization sequence was generated electronically using IBM SPSS Statistics (V 22.0, IBM Corp., Armonk, NY, USA) by author and statistician (P.G.B.) and emailed to a compounding pharmacy where batches of generic gel capsules had been filled with either cephalexin or placebo (microcrystalline cellulose and calcium carbonate powder). Four identical-looking gel capsules filled with either antibiotic (intervention) or placebo (control) were transferred to screw-top containers numbered according to the randomization sequence and sent to the recruitparticipants remained blind to group allocation during the trial.

\section{Sample Size}

A small prestudy observational trial at the practice had shown approximately $25 \%$ infection rates for flap and graft closures below the knee. Our hypothesis was that antibiotic prophylaxis would reduce the infection rate to $5 \%$. Fortyfour patients were required in each study group to show this with statistical confidence (power in excess of $80 \%$; significance level 0.05). We planned to recruit a minimum of 110 participants (55 intervention and 55 placebo), allowing for a $25 \%$ drop out.

\section{Statistical Analysis and Presentation}

Statistical analysis and result preparation followed the CONSORT guidelines [28]. Numerical data were described using mean and standard deviation when symmetrically distributed and median and interquartile range when skewed. Categorical data were presented using absolute and relative frequencies.

Eligible nonparticipants were compared with participants using unpaired ing practice in batches. Clinic staff and

t test, chi-square test, and Fisher exact test. Intervention and control group differences at baseline as well as treatment modality differences were assessed using unpaired t test, Mann-Whitney test, chisquare test, and Fisher exact test.

All data were analyzed using intention-to-treat analysis. Incidence of SSI was compared between intervention and control groups using chi-square test. The difference in infection rate was calculated and presented with $95 \%$ confidence interval $(95 \% \mathrm{CI})$. The number needed to treat for benefit was calculated with $95 \%$ CI [29]. A sensitivity analysis was conducted including all 115 patients who were originally randomized by assuming various outcome scenarios for the 5 patients who were lost to follow-up. Logistic regression models were applied to assess potential confounding effects of all baseline characteristics on difference in incidence of infection between intervention and control groups.

Chi-square and Fisher exact tests were used to compare postoperative analgesia requirements, adverse effects, and treatment of occurring infections between intervention and control groups.

Analysis was conducted using StataIC12 (StataCorp LP, Lakeway Drive, College Station, TX, USA). A P value less than 0.05 was considered statistically significant.

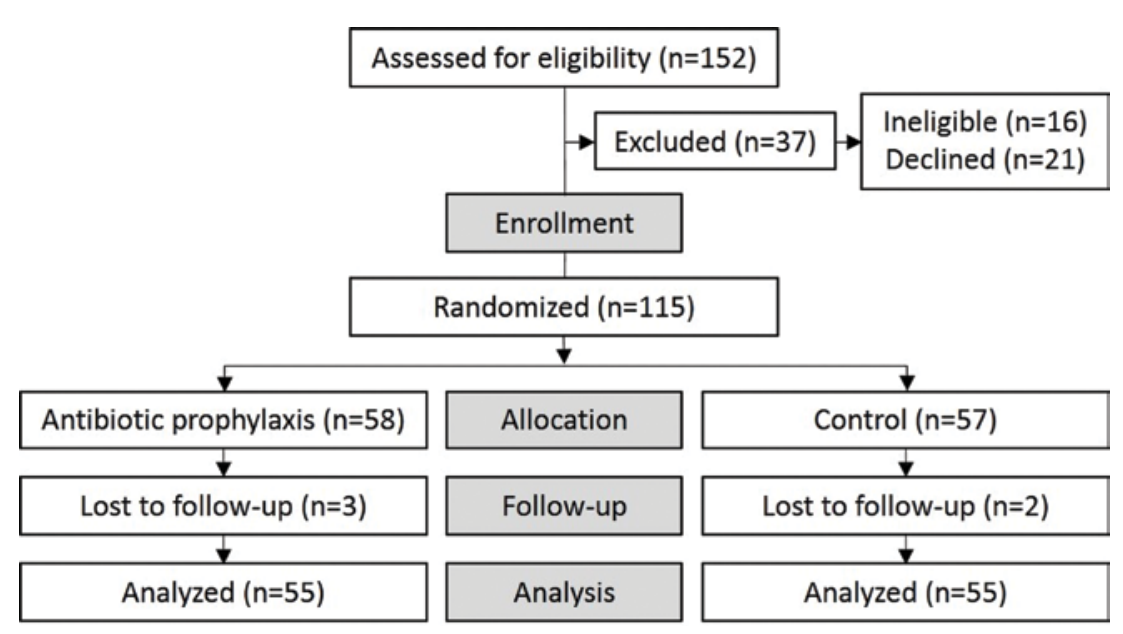

Figure 3. CONSORT Flow Diagram for Trial. [Copyright: (C2019 Rosengren et al.] 
TABLE 1. Comparison of Nonparticipants Who Fulfilled Inclusion Criteria With Those Participating in the Study

\begin{tabular}{|c|c|c|c|}
\hline Characteristic & $\begin{array}{l}\text { Nonparticipants } \\
\qquad(n=21)\end{array}$ & $\begin{array}{l}\text { Participants } \\
(n=115)\end{array}$ & P Value \\
\hline Mean age (SD), years & $71.9(12.4)$ & $69.4(10.8)$ & 0.336 \\
\hline Male $(\%)$ & $10(47.6 \%)$ & $73(63.5 \%)$ & 0.171 \\
\hline $\begin{array}{l}\text { Body site of lesion }(\%) \\
\text { Foot } \\
\text { Ankle } \\
\text { Anterior leg } \\
\text { Calf }\end{array}$ & $\begin{array}{c}1(4.8 \%) \\
1(4.8 \%) \\
15(71.4 \%) \\
4(19.0 \%)\end{array}$ & $\begin{array}{c}8(7.0 \%) \\
6(5.2 \%) \\
44(38.3 \%) \\
57(49.6 \%)\end{array}$ & 0.030 \\
\hline $\begin{array}{l}\text { Histologya }(\%) \\
\text { BCC } \\
\text { SCC } \\
\text { Keratoacanthoma } \\
\text { Melanoma } \\
\end{array}$ & $\begin{aligned} & 6(30.0 \%) \\
& 11(55.0 \%) \\
& 2(10.0 \%) \\
& 1(5.0 \%) \\
&\end{aligned}$ & $\begin{array}{c}54(47.0 \%) \\
48(41.7 \%) \\
7(6.1 \%) \\
6(5.2 \%) \\
\end{array}$ & 0.059 \\
\hline Active smoker ${ }^{\mathrm{a}}(\%)$ & 0 & $2(1.7 \%)$ & 1.0 \\
\hline Type 2 diabetes mellitus ${ }^{a}(\%)$ & $1(5.0 \%)$ & $13(11.3 \%)$ & 0.693 \\
\hline $\begin{array}{l}\text { User of anticoagulant } \\
\text { medication }^{\mathrm{a}}(\%)\end{array}$ & 0 & $27(23.5 \%)$ & 0.065 \\
\hline $\begin{array}{l}\text { User of immunosuppressive } \\
\text { medication }^{\mathrm{a}}(\%)\end{array}$ & 0 & $1(0.9 \%)$ & 1.0 \\
\hline
\end{tabular}

$\mathrm{BCC}=$ basal cell carcinoma; $\mathrm{SCC}=$ squamous cell carcinoma; $\mathrm{SD}=$ standard deviation .

${ }^{a}$ Missing information for 1 nonparticipant.

\section{Results}

Sixteen of 152 consecutive patients requiring flap or graft closures below the knee were ineligible for this study because of penicillin or cephalosporin allergy $(\mathrm{n}=9)$, taking antibiotics for unrelated reasons at the time of surgery $(\mathrm{n}=4)$, and previous participation in this study $(\mathrm{n}=3)$.

Twenty-one eligible patients declined to participate. The most common reasons given for nonparticipation were not wanting to take unnecessary tablets $(\mathrm{n}=12)$ and fear of possible diarrhea ( $\mathrm{n}$ $=3)$. Other reasons given $(n=6)$ were being too old, fear of allergy, and being unwell on the day of the procedure.

With the exception of site tumor, there was no difference between eligible nonparticipants and participants (Table 1). Nonparticipants were more likely to have the neoplasm on the anterior leg whereas participants were more likely to have it on the calf $(\mathrm{P}=0.030)$ (Table 1$)$.
Of the 115 participants, 57 were randomized to administration of placebo (control group) and 58 to administration of cephalexin (intervention group). The 2 study groups were comparable at baseline for all variables measured (age, sex, diabetes, smoking status, anticoagulant or immunosuppressive medication, anatomical site and histology of tumor, defect size, and repair technique) (Table 2). Defect closure was with flap repair for 106 (52 control, 55 intervention) participants and graft repair for 8 (5 control, 3 intervention) participants. The remaining participant had an elliptical closure. Graft repair in all cases was with split thickness skin taken from the area surrounding the defect. This method of graft closure is referred to as a halo graft [30].

Two participants (both intervention) violated protocol and were withdrawn from the study, one because the treating doctor opted to close the defect with an ellipse and the other because of needing antibiotic treatment for an unrelated SSI during the study follow-up period. Three participants ( 2 controls, 1 intervention) were lost to follow-up despite repeated attempts at phone contact. There were no demonstrable differences between the characteristics of the 5 participants who did not complete the study and the 110 who did.

\section{Surgical Site Infection}

The main analysis based on available cases at follow-up (Table 3) showed 17 $(30.9 \% ; n=55)$ SSIs for control and 14 $(25.5 \% ; n=55)$ for intervention participants $(\mathrm{P}=0.525)$. A sensitivity analysis including all 115 initially randomized patients did not alter this result, regardless of whether the patients who were lost to follow-up were assumed to have had an infection or not to have had an infection (Table 3). Logistic regression analyses to assess effects of possible confounding variables did not alter the main result of the trial. Only 1 (intervention) of 8 split thickness graft closures developed SSI. All other cases of SSI occurred in flap closures.

The difference in infection rate between the control and intervention groups was $5.4 \%$ (95\% CI: $11.4 \%$ $22.2 \%$ ). Nineteen patients needed to be treated (number needed to benefit) to prevent an infection. The power to detect the $5.4 \%$ difference in infection rates between intervention and control groups was $9.6 \%$. A sample size of 1,089 participants in each group would have been needed to reach a power of $80 \%$.

\section{Secondary Outcome Measures}

There was no difference in analgesia requirement between study groups, with the majority of participants $(81.8 \%$ of controls; $78.2 \%$ of intervention group) taking no postoperative analgesia (Table 4). One patient in the intervention group reported nausea in the follow-up period. No other symptoms that might have been attributable to the intervention were recorded in either study group. 


\section{Swab Results for SSI Cases}

All patients with clinical SSI were treated with antibiotics, the majority (16/17 controls and 12/14 intervention participants) receiving cephalexin (Table 4).

Doctors forgot to take swabs for microscopy, culture, and sensitivity in 5 participants presenting to the study clinic with suspected SSI. A further 5 study participants presented to clinicians elsewhere (hospital in 2 cases, own family doctor in 3 cases) with suspected SSI and were treated with antibiotics without first taking swabs.

Of the 10 participants ( 5 control, 5 intervention) with suspected SSI not confirmed on microscopy, 8 were treated with cephalexin and 1 with dicloxacillin. In the final case, we were unable to ascertain what antibiotic had been prescribed. Clinical SSI settled in all 10 cases without the need for further intervention.

Of the 21 swabs taken, 12 ( 8 control, 4 intervention) grew Staphylococcus aureus sensitive to cephalexin, 1 (intervention) produced Stenotrophomonas maltophilia sensitive to cephalexin, and a further 4 ( 2 control, 2 intervention) developed no organism. Clinical SSI in all of these 17 swabbed cases responded fully to cephalexin which had been prescribed.
TABLE 2. Baseline Comparison of Control Group

$(\mathrm{n}=57)$ With Intervention Group $(\mathrm{n}=58)$

\begin{tabular}{|c|c|c|c|}
\hline Characteristic & $\begin{array}{l}\text { Control } \\
(n=57)\end{array}$ & $\begin{array}{l}\text { Intervention } \\
\quad(n=58)\end{array}$ & P Value \\
\hline Mean age (SD), years & $69.4(11.6)$ & $69.4(10.1)$ & 0.982 \\
\hline Male $(\%)$ & $34(59.6 \%)$ & $39(67.2 \%)$ & 0.398 \\
\hline $\begin{array}{l}\text { Body site of lesion }(\%) \\
\text { Foot } \\
\text { Ankle } \\
\text { Anterior leg } \\
\text { Calf } \\
\end{array}$ & $\begin{array}{c}3(5.3 \%) \\
2(3.5 \%) \\
21(36.8 \%) \\
31(54.4 \%) \\
\end{array}$ & $\begin{array}{c}5(8.6 \%) \\
4(6.9 \%) \\
23(39.7 \%) \\
26(44.8 \%) \\
\end{array}$ & 0.633 \\
\hline $\begin{array}{l}\text { Histology }(\%) \\
\text { BCC } \\
\text { SCC } \\
\text { Keratoacanthoma } \\
\text { Melanoma }\end{array}$ & $\begin{array}{c}30(52.6 \%) \\
18(33.4 \%) \\
5(8.8 \%) \\
3(5.3 \%)\end{array}$ & $\begin{array}{c}24(41.4 \%) \\
29(50 \%) \\
2(3.4 \%) \\
3(5.2 \%)\end{array}$ & 0.412 \\
\hline Active smoker $(\%)$ & $1(1.8 \%)$ & $1(1.7 \%)$ & 1.0 \\
\hline Type 2 diabetes mellitus (\%) & $7(12.3 \%)$ & $6(10.3 \%)$ & 0.777 \\
\hline $\begin{array}{l}\text { User of anticoagulant } \\
\text { medication }(\%)\end{array}$ & $10(17.6 \%)$ & $17(29.3 \%)$ & 0.248 \\
\hline $\begin{array}{l}\text { Repair technique } \\
\text { Ellipse } \\
\text { ROM flap } \\
\text { Keystone flap } \\
\text { Rotation } \\
\text { A-T flap } \\
\text { Other transposition flap } \\
\text { Other advancement flap } \\
\text { Split thickness (halo) graft }\end{array}$ & $\begin{array}{l}0 \\
31(54.4 \%) \\
6(10.5 \%) \\
6(10.5 \%) \\
6(10.5 \%) \\
2(3.5 \%) \\
1(1.8 \%) \\
5(8.8 \%) \\
\end{array}$ & $\begin{aligned} & 1(1.7 \%)^{\mathrm{a}} \\
& 28(48.3 \%) \\
& 7(12.1 \%) \\
& 7(12.1 \%) \\
& 8(13.8 \%) \\
& 3(5.2 \%) \\
& 1(1.7 \%) \\
& 3(5.2 \%) \\
&\end{aligned}$ & 0.970 \\
\hline $\begin{array}{l}\text { Median average diameter } \\
\text { defect size }\end{array}$ & 20.0 & 20.0 & 0.335 \\
\hline (IQR), mm & $(16,22)$ & $(16,24.5)^{\mathrm{b}}$ & \\
\hline
\end{tabular}

$\mathrm{BCC}=$ basal cell carcinoma; IQR = interquartile range; $\mathrm{SCC}=$ squamous cell carcinoma; $\mathrm{SD}$ = standard deviation; $\mathrm{ROM}$ = reducing opposed multilobed flap.

${ }^{\text {a }}$ Patient receiving ellipse repair technique was removed from follow-up.

${ }^{\mathrm{b}}$ Based on 57 patients.

TABLE 3. Sensitivity Analysis of Surgical Site Infection by Intention to Treat

\begin{tabular}{|l|c|c|c|c|c|}
\hline & Control Group & $\begin{array}{c}\text { Intervention } \\
\text { Group }\end{array}$ & $\begin{array}{c}\text { Difference: } \\
\text { Control Minus } \\
\text { Intervention }\end{array}$ & $\begin{array}{c}\text { Two-Sided } \\
\mathbf{9 5} \% \text { Cl }\end{array}$ & P Value \\
\hline $\begin{array}{l}\text { Participants who completed } \\
\text { follow-up }\end{array}$ & $\begin{array}{c}17 / 55 \\
(30.9 \%)\end{array}$ & $\begin{array}{c}14 / 55 \\
(25.5 \%)\end{array}$ & $5.4 \%$ & $-11.4,22.2$ & 0.525 \\
\hline Sensitivity analysis & $\begin{array}{c}17 / 57 \\
(29.8 \%)\end{array}$ & $\begin{array}{c}14 / 58 \\
(24.1 \%)\end{array}$ & $5.7 \%$ & $-10.5,21.9$ & 0.492 \\
\hline $\begin{array}{l}\text { Assuming all lost to follow- } \\
\text { up did not develop SSI }\end{array}$ & $\begin{array}{c}17 / 58 \\
(29.3 \%)\end{array}$ & $4.0 \%$ & $-12.9,20.9$ & 0.642 \\
\hline $\begin{array}{l}\text { Assuming all lost to follow- } \\
\text { up did develop SSI }\end{array}$ & $(33.3 \%)$ &
\end{tabular}

$\mathrm{CI}=$ confidence interval; SSI $=$ surgical site infection. 
TABLE 4. Comparison of Analgesia Requirements, Adverse Symptoms, Follow-up Treatment, and Swab Results for Intervention and Control Study Participants

\begin{tabular}{|c|c|c|c|}
\hline Characteristic & $\begin{array}{l}\text { Control } \\
(n=55)\end{array}$ & $\begin{array}{l}\text { Intervention } \\
\quad(n=55)\end{array}$ & P Value \\
\hline Surgical site infection & $17(30.9 \%)$ & $14(25.5 \%)$ & 0.525 \\
\hline $\begin{array}{l}\text { Analgesia requirements (\%) } \\
\text { None } \\
\text { Strongest paracetamol } \\
\text { Strongest Panadeine } \\
\text { Strongest Panadeine Forte } \\
\text { Strongest Endone }^{\mathrm{b}}\end{array}$ & $\begin{array}{l}45(81.8 \%) \\
8(14.5 \%) \\
0 \\
2(3.6 \%) \\
0\end{array}$ & $\begin{array}{l}43(78.2 \%) \\
11(20.0 \%) \\
0 \\
0 \\
1(1.8 \%)\end{array}$ & 0.329 \\
\hline $\begin{array}{l}\text { Adverse symptoms (\%) } \\
\text { Nausea following ingestion of study capsules } \\
\text { Diarrhea following ingestion of study capsules }\end{array}$ & $\begin{array}{l}0 \\
0\end{array}$ & $\begin{array}{l}1(1.8 \%) \\
0\end{array}$ & $\begin{array}{l}1.0 \\
1.0\end{array}$ \\
\hline $\begin{array}{l}\text { Antibiotics started }(\%) \\
\text { None } \\
\text { Cephalexin } \\
\text { Dicloxacillin } \\
\text { Unknown antibiotic started by nonpractice doctor }\end{array}$ & $\begin{array}{l}38(69.1 \%) \\
16(29.1 \%) \\
0 \\
1(1.8 \%) \\
\end{array}$ & $\begin{aligned} & 41(74.5 \%) \\
& 12(21.8 \%) \\
& 1(1.8 \%) \\
& 1(1.8 \%) \\
&\end{aligned}$ & 0.753 \\
\hline $\begin{array}{l}\text { Swab result }(\%)(\mathrm{n}=21) \\
\text { S aureus sensitive to cephalexin } \\
\text { S aureus sensitive to cephalexin }+2 \text { nd organism } \\
\text { not sensitive to cephalexin } \\
\text { Other organism sensitive to cephalexin } \\
\text { Other organism not sensitive to cephalexin } \\
\text { Normal skin flora }\end{array}$ & $\begin{array}{l}8(\%) \\
1(\%) \\
0 \\
1(\%) \\
2(\%)\end{array}$ & $\begin{array}{l}4(\%) \\
1(\%) \\
1(\%) \\
1(\%) \\
2(\%)\end{array}$ & 0.879 \\
\hline
\end{tabular}

a Paracetamol and codeine.

${ }^{\mathrm{b}}$ Oxycodone.

In 4 participants with SSI, the infection did not respond to cephalexin. Swabs in 2 cases ( 1 intervention, 1 control) isolated organisms not sensitive to cephalexin (Pseudomonas aeruginosa in one case, Enterobacter cloacae in the other). In a further 2 participants (1 control, 1 intervention), 2 organisms were isolated on microscopy and culture: the $S$ aureus found in each case was sensitive to cephalexin but the second organism isolated ( $P$ aeruginosa in one case and Streptococcus C in the other) was not sensitive to cephalexin. Ciprofloxacin was introduced for each SSI not responding to cephalexin, in accordance with swab sensitivity results.

\section{Discussion}

The results of this trial did not show any clinically or statistically significant reduction in the rate of SSI from a single dose of cephalexin administered 40-60 minutes before skin incision. There was no increase in adverse outcomes related to antibiotic administration in the intervention group.

These results contrast to the only previously identified study examining the effect of antibiotic prophylaxis in lower limb ellipse skin excisions, which showed a reduction in the incidence of SSI from a similar baseline rate of $35.7 \%$ to a rate of $12.5 \%$ in the intervention group, although this study was underpowered to produce statistical significance [17]. Our study differed in that we included only below-knee excisions, which are at higher risk than the entire lower limb, and flap and graft surgery, which are at higher infection risk than ellipse excisions.

Other studies examining antibiotic prophylaxis for surgical sites elsewhere have also demonstrated the effectiveness of antibiotic prophylaxis, in contrast with our study. Two RCTs-one involving flap and graft repairs in a dermatological surgery setting [31] and the other involving ear and nose only [32] — confirmed that single-dose oral antibiotic prophylaxis prevented SSI. Although a further RCT involving graft repairs on the nose was underpowered to show a reduction in SSI, graft survival was better for those randomized to antibiotic prophylaxis [33]. A recent meta-analysis of 12 RCTs studying antibiotic prophylaxis in dermatological surgery demonstrated that preoperative antibiotic prophylaxis was effective in preventing SSI and furthermore that single antibiotic use is of adequate efficacy and safety for preventing SSI [34]. It should be noted, however, that only 2 of these RCTs investigated oral antibiotic prophylaxis, with intravenous antibiotics investigated in the remaining 10 studies [34]. 
The recruited cases for this study were at particularly high infection risks, and we postulate that this was the reason for the failure of antibiotic prophylaxis in our study. First, the anatomical site studied was below the knee, which has been shown to have higher risk of infection than other anatomical sites $[13,16]$. Second, only flap and graft surgery was included, which is known to be of higher SSI risk than simpler surgical techniques [20]. Third, the study was conducted in a tropical setting, where infection rates have previously been shown to be increased $(8.6 \%$ and $11.7 \%$ in studies in the Mackay region) $[35,36]$. The reason for this remains unclear, but might be related to tropical humidity. We hypothesize that a single-dose antibiotic prophylaxis was simply insufficient in dose and duration to prevent SSI in these circumstances.

Minimizing antibiotic dose and duration is an increasingly important focus of research [37]. Given the advantages of prophylactic antibiotics in reducing morbidity, and potentially reducing the total amount of antibiotic prescribed [17], we would recommend that future research investigate other prophylactic regimens, such as larger or multiple pre- or perioperative doses of antibiotic or antibiotic mixed with local anesthetic and injected directly into the wound site preoperatively [38,39].

The strengths of our study were a blind, randomized design with placebo control, a standardized protocol for excision and follow-up, as well as the collection of a large amount of demographic, medical, and excision-related data for comparison of groups.

We must, however, acknowledge some limitations to our study. Infection may have been underreported, with participants presenting to doctors outside the study practice after surgery. Various characteristics influence SSI, and although information on as many variables as possible was recorded, it is difficult to ensure that all possible variables are comparable at baseline. Despite the intention to take swabs for microscopy culture and sensitivity for all cases of clinical SSI, only 21 swabs were taken in 31 suspected SSI cases.

There may also be limitations to generalizing our findings. This study included complex procedures only, and we do not know the effect of this regimen for elliptical excisions albeit that few nasal and aural skin cancers can be effectively excised with an ellipse. The climate in North Queensland is hot and humid, with a mean daily maximum temperature ranging between $24.2^{\circ} \mathrm{C}$ and $30^{\circ} \mathrm{C}$ during the summer months and a relative humidity of $75 \%-79 \%$. The results may not necessarily be generalizable to a temperate climate with a lower baseline infection rate.

The diagnosis of infection, even when guidelines are used, is subjective, and interobserver and intraobserver variation may occur [40]. However, the definition we used is the most widely implemented standard definition of wound infection [27].

\section{Conclusions}

Despite confirmation that the majority of complex belowknee closure SSIs responded effectively to oral cephalexin postoperatively, we were unable to demonstrate that a single preoperative 2-g dose of cephalexin could prevent SSI from occurring.

Infection rates for below-knee surgery are unacceptably high, even in temperate climates. As antibiotic prophylaxis has been shown to be helpful for other dermatological highrisk areas, further research experimenting with different antibiotic prophylactic regimens is worthwhile.

\section{Acknowledgments}

We thank trial recruiting doctors (Drs. Alan Poggio, Jeremy Hudson, Robert Teunisse, Lauren Barcley, Sandra Steele, Michael Khong, and Abid Vitani), the trial clinical nurse (Lyndie Terry), and data collection personnel (Lorraine Fisher, Lynne Kelly, and Angela Byers). We also thank Dr Pranav Divakarum and Dr Leanne Hall for their help in preparing the manuscript.

\section{References}

1. Haas AF, Grekin RC. Antibiotic prophylaxis in dermatologic surgery. J Am Acad Dermatol. 1995;32(2 Pt 1):155-176.

2. Dettenkofer M, Wilson C, Ebner W, Norgauer J, Rüden H, Daschner FD. Surveillance of nosocomial infections in dermatology patients in a German university hospital. Br J Dermatol. 2003;149(3):620-623.

3. Dixon AJ, Dixon MP, Askew DA, Wilkinson D. Prospective study of wound infections in dermatologic surgery in the absence of prophylactic antibiotics. Dermatol Surg. 2006;32(6):819-826.

4. Culver DH, Horan TC, Gaynes RP, et al. Surgical wound infection rates by wound class, operative procedure, and patient risk index. Am J Med. 1991;91(3):S152-S157.

5. Cruse PJE, Foord R. The epidemiology of wound infection: a 10year prospective study of 62,939 wounds. Surg Clin North Am. 1980;60(1):27-40.

6. Maragh SL, Otley CC, Roenigk RK, Phillips PK. Antibiotic prophylaxis in dermatologic surgery: updated guidelines. Dermatol Surg. 2005;31(1):83-91.

7. Rosengren H, Dixon A. Antibacterial prophylaxis in dermatologic surgery: an evidence-based review. Am J Clin Dermatol. 2010;11(1):35-44.

8. Wright TI, Baddour LM, Berbari EF, et al. Antibiotic prophylaxis in dermatologic surgery: advisory statement 2008. J Am Acad Dermatol. 2008;59(3):464-473.

9. Del Rosso JQ. Wound care in the dermatology office: where are we in 2011? J Am Acad Dermatol. 2011;64(3 Suppl):S1-S7.

10. Penington A. Ulceration and antihypertensive use are risk factors for infection after skin lesion excision. ANZ J Surg. 2010;80(9):642-645.

11. Dixon AJ, Dixon MP, Dixon JB. Prospective study of skin surgery in patients with and without known diabetes. Dermatol Surg. 2009;35(7):1035-1040. 
12. Wahie S, Lawrence CM. Wound complications following diagnostic skin biopsies in dermatology inpatients. Arch Dermatol. 2007;143(10):1267-1271.

13. Heal C, Buettner P, Browning S. Risk factors for wound infection after minor surgery in general practice. Med J Aust. 2006;185(5):255-258.

14. Lathlean S. Skin cancer in general practice in South Australia: a five year study. Aust Fam Physician. 1999;(28 Suppl 1):S28-S31.

15. Bordeaux JS, Martires KJ, Goldberg D, Pattee SF, Fu P, Maloney ME. Prospective evaluation of dermatologic surgery complications including patients on multiple antiplatelet and anticoagulant medications. J Am Acad Dermatol. 2011;65(3):576-583.

16. Heal CF, Buettner PG, Drobetz H. Risk factors for surgical site infection after dermatological surgery. Int J Dermatol. 2012;51(7)796-803.

17. Smith SC, Heal CF, Buttner PG. Prevention of surgical site infection in lower limb skin lesion excisions with single dose oral antibiotic prophylaxis: a prospective randomised placebo-controlled double-blind trial. BMJ Open. 2014;4(7):e005270.

18. Sylaidis P, Wood S, Murray DS. Postoperative infection following clean facial surgery. Ann Plast Surg. 1997;39(4):342-346.

19. Rosengren H, Heal C, Smith S. An update on antibiotic prophylaxis in dermatologic surgery. Curr Dermatol Rep. 2012;1(2):5563.

20. Amici JM, Rogues AM, Lasheras A, et al. A prospective study of the incidence of complications associated with dermatological surgery. Br J Dermatol. 2005;153(5):967-971.

21. Rossi AM, Mariwalla K. Prophylactic and empiric use of antibiotics in dermatologic surgery: a review of the literature and practical considerations. Dermatol Surg. 2012;38(12):1898-1921.

22. Goossens H, Ferech M, Vander Stichele R, Elseviers M; ESAC Project Group. Outpatient antibiotic use in Europe and association with resistance: a cross-national database study. Lancet. 2005;365(9459):579-587.

23. Costelloe C, Metcalfe C, Lovering A, Mant D, Hay AD. Effect of antibiotic prescribing in primary care on antimicrobial resistance in individual patients: systematic review and meta-analysis. BMJ. 2010;340:c2096.

24. Moorhead C, Torres A. I PREVENT bacterial resistance: an update on the use of antibiotics in dermatologic surgery. Dermatol Surg. 2009;35(10):1532-1538.

25. Burke JP. Maximizing appropriate antibiotic prophylaxis for surgical patients: an update from LDS Hospital, Salt Lake City. Clin Infect Dis. 2001;33 Suppl 2:S78-S83.

26. Classen DC, Evans RS, Pestotnik SL, Horn SD, Menlove RL, Burke JP. The timing of prophylactic administration of antibiotics and the risk of surgical-wound infection. $N$ Engl J Med. 1992;326(5):281-286.
27. Garner JS, Jarvis WR, Emori TG, Horan TC, Hughes JM. CDC definitions for nosocomial infections, 1988. Am J Infect Control. 1988;16(3):128.

28. Altman D, Moher D, Schulz KF; The CONSORT Group. CONSORT 2010 Statement. http://www.consort-statement.org/consort-2010. 2014. Accessed June 1, 2018

29. Altman DG. Confidence intervals for the number needed to treat. BMJ. 1998;317(7168):1309.

30. Paul SP. "Halo" grafting: a simple and effective technique of skin grafting. Dermatol Surg. 2010;36(1):115-119.

31. Amland PF, Andenaes K, Samdal F, et al. A prospective, doubleblind, placebo-controlled trial of a single dose of azithromycin on postoperative wound infections in plastic surgery. Plast Reconstr Surg. 1995;96(6):1378-1383.

32. Rosengren H, Heal CF, Buttner PG Effect of a single prophylactic preoperative oral antibiotic dose on surgical site infection following complex dermatological procedures on the nose and ear: a prospective, randomised, controlled, double-blinded trial. BMJ Open. 2018;8:e20213.

33. Kuijpers DI, Smeets NWJ, Lapière K, Thissen MRTM, Krekels GAM, Neumann HAM. Do systemic antibiotics increase the survival of a full thickness graft on the nose? J Eur Acad Dermatol Venereol. 2006;20(10):1296-1301.

34. Zhang Y, Dong J, Qiao Y, He J, Wang T, Ma S. Efficacy and safety profile of antibiotic prophylaxis usage in clean and cleancontaminated plastic and reconstructive surgery: a meta-analysis of randomized controlled trials. Ann Plast Surg. 2014;72(1):121130.

35. Heal C, Buettner P, Raasch B, et al. Can sutures get wet? Prospective randomised controlled trial of wound management in general practice. BMJ. 2006;332(7549):1053-1056.

36. Heal C, Buettner P, Cruickshank, et al. Does single application of topical chloramphenicol to high risk sutured wounds reduce incidence of wound infection after minor surgery? Prospective randomised placebo controlled double blind trial. $B M J$. 2009;338:a2812.

37. Llewelyn MJ, Fitzpatrick JM, Darwin E, et al. The antibiotic course has had its day. BMJ. 2017;358:j3418.

38. Griego RD, Zitelli JA. Intra-incisional prophylactic antibiotics for dermatologic surgery. Arch Dermatol. 1998;134(6):688-692.

39. Huether MJ, Griego RD, Brodland DG, Zitelli JA. Clindamycin for intraincisional antibiotic prophylaxis in dermatologic surgery. Arch Dermatol. 2002;138(9):1145-1148.

40. Bruce J, Russell EM, Mollison J, Krukowski ZH. The quality of measurement of surgical wound infection as the basis for monitoring: a systematic review. J Hosp Infect. 2001;49(2):99-108. 